\title{
PENGARUH LINGKUNGAN KERJA TERHADAP KINERJA KARYAWAN PADA SUATU PERUSAHAAN DI JAKARTA
}

\author{
Ulva Ardhianti ${ }^{1}$, Ade Irma Susanty ${ }^{2}$ \\ ${ }^{1.2}$ Prodi S1 Administrasi Bisnis, Fakultas Komunikasi dan Bisnis, Universitas Telkom \\ 11ulvaardhianti.student@telkomuniversity.ac.id, ${ }^{2}$ adeirma@telkomuniversity.ac.id
}

\begin{abstract}
A company requires to have a good quality of employees in order to achieve an optimal performance. One of the ways to achieve a good quality of employees is by paying attention to their work environment in order to create a comfortable work atmosphere. In this current era, most of the companies have realized about the change of generations that requires them to have more open, flexible, and comfortable work environment.

This research aims to portray two types of work environments that consist of physical and non-physical work environment. Moreover, the technique used for this research is the non probability sampling technique based on 31 respondents from a company in Jakarta. Furthermore, this research used descriptive quantitative method with the analysis of Simple Linear Regression

Descriptive analysis result shows that both of the physical and non-physical work environment variable are in the good category. Likewise, the performance variable is also in the good category. Moreover, based on the analysis of determination coefficient, the quantity of the R-square is 0.575 . It means that $57.5 \%$ of employees performance is influenced by their work environment. While the remaining $42.5 \%$ (100\% - 57.5\%) is influenced by the other variables besides the work environment. In addition, $T$ test result shows that $T$ arithmetic is greater than T table (6.262> 2.045), and the significance is less than $0.05(0.000<0.05)$ which means that the work environment has a significant impact for the company's performance. Thus, company needs to consider work environment as a crucial factor that can improve the employees performance. Therefore, if company wants to improve the performance, improving the work environment is one of the ways to achieve that goal.
\end{abstract}

Keywords: Physical Work Environment, Non-Physical Work Environment, Employee Performance

\begin{abstract}
Abstrak : Perusahaan harus memiliki sumber daya manusia (SDM) yang berkualitas untuk mencapai hasil kinerja yang baik agar perusahaan dapat mencapai tujuannya. Salah satu cara perusahaan dalam meningkatkan kinerja para karyawannya yaitu dengan memperhatikan lingkungan kerja karyawan di dalam kantor agar tercipta atmosfer yang nyaman bagi karyawan dalam melakukan pekerjaannya.Saat ini perusahaan menyadari bahwa adanya perubahan generasi sehingga menuntut perubahan lingkungan kerja yang lebih terbuka, fleksibel dan nyaman.

Penelitian ini bertujuan untuk mengetahui lingkungan kerja, yang terdiri dari lingkungan kerja fisik dan non fisik serta bagaimana pengaruhnya terhadap kinerja karyawan. Penelitian ini menggunakan teknik sampling nonprobability sampling dengan 31 respondendari suatu perusahaan di Jakarta. Penelitian ini menggunakan metode kuantitatif , deskriptif dan analisis yang digunakan dalam penelitian iniadalah Analisis Regresi Linier Sederhana.

Hasilanalisis deskriptif pada penelitian ini menunjukan bahwa variabel lingkungan kerja fisik maupun non fisik masuk ke dalam kategori baik. Variable kinerja juga ada pada kategori baik. Dari analisis koefisien determinasi besarnya nilai $R$-square adalah 0,575. Berarti 57,5\% kinerja karyawan dipengaruhi oleh lingkungan kerjanya, sisanya 42,5\% dipengaruhi oleh variabel lain selain lingkungan kerja. Demikian pula hasil uji t menunjukkan bahwa t hitung lebih besar daripada $t$ tabel $(6,262>2,045)$ dan signifikasi lebih kecil dari $0,05(0,000<0,05)$ yang berarti lingkungan kerja berpengaruh signifikan terhadap kinerja. Dengan demikian, maka perusahaan perlu mempertimbangkan lingkungan kerja sebagai faktor yang dapat meningkatkan kinerja karyawan. Artinya, jika perusahaan ingin meningkatkan kinerja maka perbaikan lingkungan kerja merupakan salah satu cara yang dapat dilakukan.
\end{abstract}


Kata kunci : Lingkungan Kerja Fisik, Lingkungan Kerja Non Fisik dan Kinerja Karyawan

\section{A. PENDAHULUAN \\ 1.1 Latar Belakang}

Dalam studi manajemen sumber daya manusia, lingkungan kerja merupakan salah satu faktor yang dapat meningkatkan kinerja.Data dari Badan Perencanaan Pembangunan Nasional (Bappenas) dalam IDN Media menyatakan ada 63 juta penduduk Indonesia adalah millennial atau penduduk usia 20 - 35 tahun (Utomo, 2019). Mereka ada di usia produktif dan beberapa sudah masuk dalam dunia kerja.Menurut artikel dari Wirotama (2017)Generasi milenial memiliki perbedaan pola pikir dan tingkah laku dibandingkan dengan generasi lainnya. Generasi millennialmenuntut perubahan lingkungan kerja yang lebih terbuka, fleksibel dan nyaman untuk meningkatkan kinerjanya dalam bekerja.

Erry dalam Suwondo dan Sutanto (2015) menyatakan bahwa konsep ruang kerja terbukamerupakan upaya yang dilakukan perusahaan dalam menciptakanatmosferkerjatanpabatas, contohnya kantor Google Indonesia. Kantor Google Indonesia meminimalisir pembatas pada ruang kerja karyawan agar karyawan dapat melakukan pekerjaannya secara fleksibel. Kompas.com mendeskribsikan bahwa kantor Google Indonesia menyediakan ruang diskusi,ruang bermain, ruang santai dan ruang serbaguna lainnya (Bohang, 2018). Ini menandakan bahwa Google tidak mewajibkan karyawannya bekerja hanya di ruang kerjanya saja. Fasilitas yang disediakan kantor Google Indonesia bertujuan untuk menciptakan atmosfer bekerja yang nyaman bagi karyawan terutama karyawan generasi millennials sehingga tercipta ide ide kreatif dari karyawan.

Pada suatu perusahaan di Jakarta yang menjadi objek pada penelitian ini bermaksud melakukan perubahan lingkungan kerja di kantornya karena menyadari bahwa hampir $60 \%$ karyawannya adalah karyawan generasi millennials yang sudah membutuhkan lingkungan kerja yang sesuai dengan karakteristik generasi mereka. Namun demikian sebelum melakukan perubahan lingkungan kerja, perlu penelitian terlebih dahulu karena investasi untuk melakukan perubahan lingkungan kerja cukup tinggi. Oleh karena itu, agar investasi yang dikeluarkan dalam melakukan perubahan lingkungan kerja perusahaan lebih efisien dan efektif maka perlu dilakukan pengkajian terlebih dahulu. Berdasarkan hasil penelitian yang dilakukan Ningrum (2014) Lingkungan kerja fisik dan lingkungan kerja non fisik berpengaruh signifikan terhadap kinerja karyawan.

Robins dalam Rahmawanti (2014) mengemukakan bahwa adanya hubungan yang erat antara lingkungan kerja terhadap kinerja karyawan. Karyawan menaruh perhatian yang cukup besar terhadap lingkungan kerja mereka, baik dalam segi kenyamanan pribadi maupun kemudahan karyawan dalam melakukan pekerjaannya. Terciptanya lingkungan kerja yang baik akan berpengaruh terhadap kinerja karyawan

Berdasarkan pemaparan latar belakang tersebut, maka penelitian ini bertujuan untuk melihat seberapa signifikan pengaruh lingkungan kerja terhadap kinerja karyawan.

\section{TINJAUAN PUSTAKA}

Menurut Sedarmayanti (2015) Manajemen Sumber Daya Manusia merupakan kebijakan tentang aspek manusia, meliputi merekrut karyawan, memilih karyawan, menambah karyawan, memberi pelatihan kepada karyawan dan memberi motivasi kepada karyawan.

Siagian (2014) mengemukaan lingkungan kerja merupakan lingkungan pegawai melaksanakan pekerjaannya atau kegiatannya sehari - hari di kantor. Menurut Siagian (2014) lingkungan kerja terbagi dua yaitu; lingkungan kerja non fisik dan lingkungan kerja fisik.

Menurut Sedarmayanti (2013)lingkungan kerja fisik merupakan keadaan fisik yang ada disekitar tempat karyawan bekerja, lingkungan kerja fisik ini mampu mempengaruhi karyawan dalam melakukan pekerjaannya secara langsung maupun tidak langsung. Lebih lanjut Sedarmayanti (2013) menyatakan bahwa lingkungan kerja non fisik merupakan seluruh keadaan non fisik yang ada di sekitar tempat karyawan bekerja seperti hubungan kerja yang baik 
dengan atasan, bawahan, sesama rekan kerja dan lainnya yang dapat mempengaruhi karyawan dalam melakukan pekerjaannya.

Menurut Soetjipto dalam Gustian (2016) dimensi lingkungan kerja yang terdiri dari lingkungan kerja fisik dan non fisik adalah pencahayaan, sirkulasi udara, kebisingan, warna, kelembaban udara, fasilitas, hubungan yang harmonis, kesempatan untuk maju dan keamanan dalam pekerjaan.

Hamali (2016) kinerja adalah hasil pekerjaan yang memiliki hubungan yang sangat kuat dengan tujuan strategis organisasi, kepuasan konsumen dan memberikan kontribusi pada perekonomian. Kinerja juga merupakan pekerjaan dan hasil yang telah dicapai karyawan dalam menyelesaikan pekerjaannya menurut Miner dalam Sudarmanto (2015) dimensi kinerja karyawan terdiri dari kerjasama, kuantitas, kualitas dan penggunaan waktu kerja.

Budianto (2015) menyatakan bahwa lingkungan kerja berpengaruh signifikan terhadap kinerja karyawan. Sejalan dengan penelitian Darma (2019) bahwa lingkugan kerja berpengaruh signifikan terhadap kinerja karyawan

\subsection{KERANGKA PEMIKIRAN}

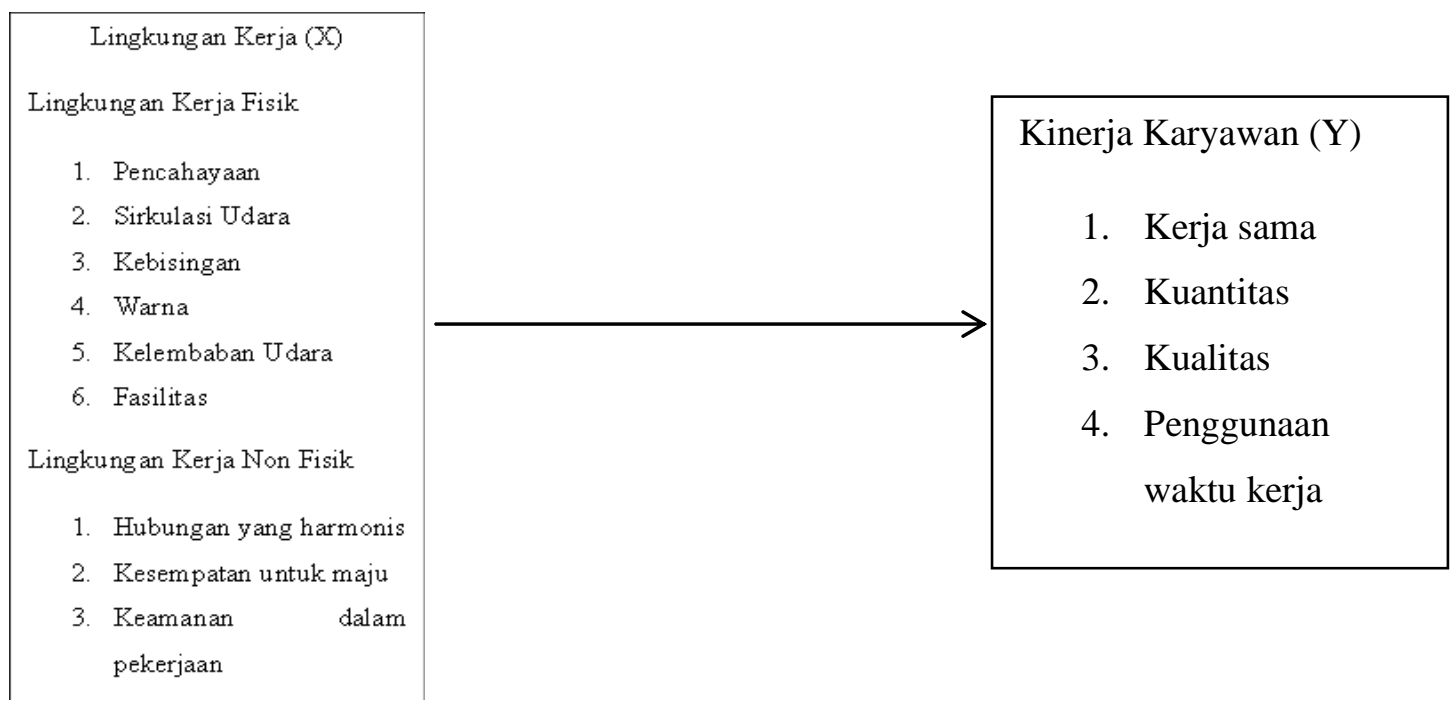

Berdasarkan kerangka pemikiran, maka peneliti mengajukan keputusan sementara (Hipotesis) bahwa Lingkungan Kerja Berpengaruh Signifikan Terhadap Kinerja Karyawan Pada suatu Perusahaan di Jakarta.

\section{B. METODE PENELITIAN}

Metode penelitian pada penelitian ini menggunakan metodedeskriptifdan kuantitatif. Dengan variable independent (X) Lingkungan Kerja dan variable (Y) Kinerja Karyawan. Dengan populasi seluruh karyawan pada suatu perushaan di Jakarta yaitu berjumlah 31 orang. Teknik sampel pada penelitian ini adalah nonprobability sampling.

Penelitian ini mengunakan skala pengukuran skala Likert (dengan skala 1 - 5). Menentukan garis kontinum adalah dengan rumus :

Nilai jarak antara presentase terbesar - Nilai jarak presentase terkecil $=100 \%-20 \%=$ $16 \%$

Skala pengukuran

5

\begin{tabular}{|c|c|c|c|c|}
$\begin{array}{c}\text { Sangat Tidak } \\
\text { Baik }\end{array}$ & Tidak Baik & Cukup Baik & Baik & Sangat Baik \\
\hline $20 \%$ & & & & \\
$52 \%$ & $68 \%$ & $84 \%$ & $100 \%$
\end{tabular}


Gambar 3.1 Klasifikasi Kategori Penilaian Persentasi dalam Garis Kontinum Sumber : Hasil Olahan Penulis (2019)

Menghitung score total dengan rumus : Responden x Nilai skala terbesar x Jumlah pertanyaan. Menghitung score ideal dengan rumus : Responden x Nilai Skala. Selanjutnya hasil presentase rata- rata score ideal dimasukan ke dalam garis kontinum.

Hasil dari uji validitas menunjukan bahwa dari 31 pernyataan dikatakan valid dengan rhitung > r-tabel dengan signifikansi 0,05 yaitu 0,355Hasil dari uji reliabilitas nilai Cronbach Alpha variable lingkungan kerja adalah 0,916 dan nilai Cronbach Alpha kinerja karyawan 0,896 dimana nilai Cornbach Alpha variable $X$ dan variable $Y>$ dari 0,7 sehingga variable $X$ dan variable Y pada penelitian ini dapat dinyatakan reliable.

\section{HASIL DAN PEMBAHASAN}

\section{a. Analisis Deskriptif}

TABEL 4.1

SKOR TOTAL VARIABEL LINGKUNGAN KERJA

\begin{tabular}{|l|l|l|l|l|}
\hline No. & Dimensi & Skor Total & Skor Ideal & $\begin{array}{l}\text { Rata- } \\
\text { Rata }\end{array}$ \\
\hline 1 & Pencahayaan & 246 & 310 & $79,3 \%$ \\
\hline 2 & Sirkulasi Udara & 242 & 310 & $78,1 \%$ \\
\hline 3 & Kebisingan & 240 & 310 & $77,4 \%$ \\
\hline 4 & Warna & 251 & 310 & $81,0 \%$ \\
\hline 5 & Kelembaban Udara & 253 & 310 & $81,6 \%$ \\
\hline 6 & Fasilitas & 243 & 310 & $78,4 \%$ \\
\hline 7 & $\begin{array}{l}\text { Hubungan } \\
\text { Harmonis }\end{array}$ & 236 & 310 & $76,1 \%$ \\
\hline 8 & Kesempatan Untuk Maju & 232 & 310 & $78,4 \%$ \\
\hline 9 & $\begin{array}{l}\text { Keamanan Dalam } \\
\text { Pekerjaan }\end{array}$ & 247 & 310 & $79,7 \%$ \\
\hline \multicolumn{2}{|l|}{ TOTAL } & $\mathbf{2 1 9 0}$ & $\mathbf{2 7 9 0}$ & $\mathbf{7 8 , 5 \%}$ \\
\hline
\end{tabular}

Sumber: Data yang diolah penulis (2020)

Pada Tabel 4.1 dapat dilihat bahwa dimensi tertinggi adalah kelembaban udaradan dimensi terendah adalah hubungan yang harmonis. Berdasarkan Tabel 4.1 di atas, posisi lingkungan kerja pada garis kontinum dapat ditunjukan pada gambar di bawah ini:

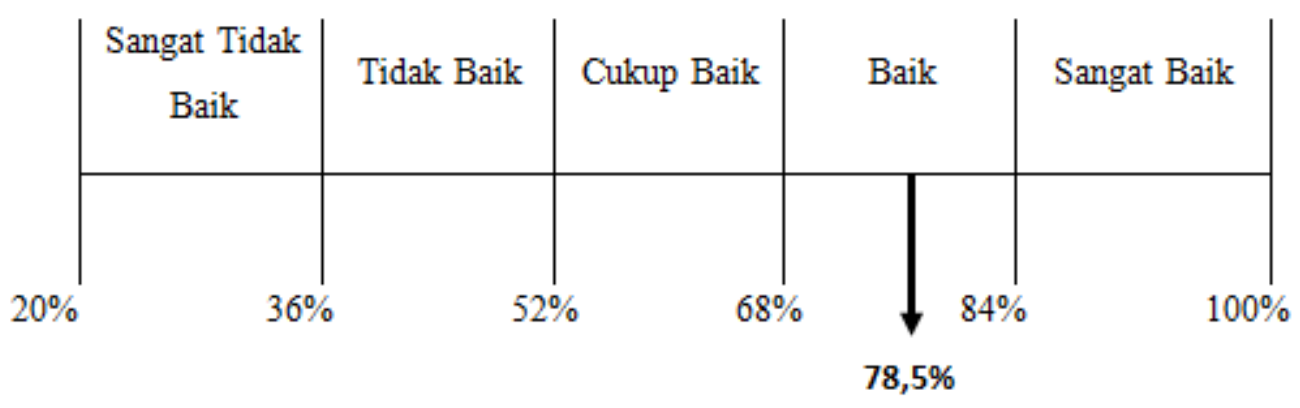

Gambar 4.1 Posisi Lingkungan Kerja Pada Garis Kontiunum Sumber : Data Oalahan Penulis(2020) 
Dari Gambar 4.1, dapat diketahui bahwa posisi lingkungan kerja pada penelitian ini ada pada kategori yang baik. dengan skor 78,5\%.

TABEL 4.2

SKOR TOTAL VARIABEL KINERJA KARYAWAN

\begin{tabular}{|l|l|l|l|l|}
\hline No. & Dimensi & Skor Total & Skor Ideal & $\begin{array}{l}\text { Rata- } \\
\text { Rata }\end{array}$ \\
\hline 1 & Kerjasama & 241 & 310 & $77,7 \%$ \\
\hline 2 & Kuantitas & 236 & 310 & $76,1 \%$ \\
\hline 3 & Kualitas & 242 & 310 & $78,1 \%$ \\
\hline 4 & Penggunaan Waktu & 243 & 310 & $78,4 \%$ \\
\hline TOTAL & & $\mathbf{9 6 2}$ & $\mathbf{1 2 4 0}$ & $\mathbf{7 7 , 6 \%}$ \\
\hline
\end{tabular}

Sumber: Data Primer yang diolah (2020)

Dalam Tabel 4.2 dapat dilihat bahwa dimensi tertinggi adalah penggunaan waktudan dimensi terendah adalah kuantitas. Berdasarkan Tabel 42 diatas, posisi kinerja karyawan pada garis kontinum dapat ditunjukan pada gambar di bawah ini:

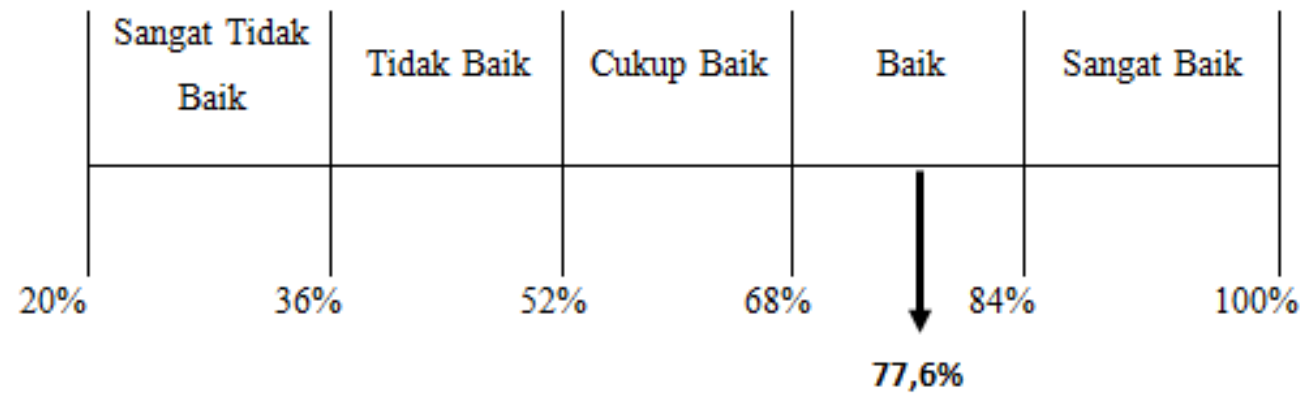

Gambar 4.2 Posisi Kinerja Karyawan Pada Garis Kontiunum

Sumber : Data Oalahan Penulis(2020)

Dari Gambar 4.2, dapat terlihat bahwa posisi kinerja karyawan pada penelitian ini ada pada kategori yang baik. dengan skor $77,6 \%$.

\section{b. Uji Hipotesis ( Uji T)}

TABEL 4.3

HASIL ANALISIS REGRESI LINIER SEDERHANA

\begin{tabular}{|c|c|c|c|c|c|c|}
\hline \multirow{2}{*}{\multicolumn{2}{|c|}{ Model }} & \multicolumn{2}{|c|}{$\begin{array}{l}\text { Unstandardized } \\
\text { Coefficients }\end{array}$} & \multirow{2}{*}{$\begin{array}{l}\text { Standardized } \\
\text { Coefficients } \\
\text { Beta } \\
\end{array}$} & \multirow[t]{2}{*}{$\mathrm{t}$} & \multirow[t]{2}{*}{ Sig. } \\
\hline & & B & Std. Error & & & \\
\hline & \begin{tabular}{|l|} 
(Constant) \\
\end{tabular} & 2,352 & 3,093 & &, 760 & .453 \\
\hline & $\begin{array}{l}\text { Lingkungan } \\
\text { Kerja }\end{array}$ & ,386 &, 062 & ,758 & 6,262 & ,000 \\
\hline
\end{tabular}

a. Dependent Variable: Kinerja Karyawan

Sumber: Data Primer yang diolah (2020)

Berdasarkan Tabel 4.3 di atas, diketahui variabel lingkungan kerja memiliki nilai thitung sebesar 6,262 dengan nilai signifikasi 0,000. Sedangkan nilai t-tabel dengan jumlah responden sebanyak $31(\mathrm{n}=31)$, variabel berjumlah $2(\mathrm{k}=2)$, dan derajat kebebasan $=\mathrm{n}-\mathrm{k}$ atau $31-2=29$ yaitu sebesar 2,045. Nilai t-hitung lebih besar dari t- 
tabel $(6,262>2,045)$ dan signifikasi lebih kecil dari $0,05(0,000<0,05)$. Dengan demikian, variabel lingkungan kerja berpengaruh signifikan terhadap kinerja karyawan di suatu perusahaan di Jakarta

c. Uji Koefisien Determinasi $\left(\mathbf{R}^{2}\right)$

TABEL 4.4

HASIL UJI KOEFISIEN DETERMINASI $\left(\mathbf{R}^{2}\right)$

\begin{tabular}{|l|l|l|l|l|}
\hline Model & $\mathrm{R}$ & R Square & $\begin{array}{l}\text { Adjusted R } \\
\text { Square }\end{array}$ & $\begin{array}{l}\text { Std. Error of } \\
\text { the Estimate }\end{array}$ \\
\hline 1 &, $758^{\mathrm{a}}$ &, 575 &, 560 & 3,53565 \\
\hline
\end{tabular}

Predictors: (Constant), Lingkungan Kerja

Dependent Variable: Kinerja Karyawan

Sumber: Data Primer yang diolah (2020)

Berdasarkan table 4.4terlihatbesarnya nilai $R$-square 0,575. Menunjukan 57,5\% kinerja karyawan di suatu perusahaan di Jakarta dipengaruhi oleh lingkungan kerjanya. Lainnya sebesar $42,5 \%$ dipengaruhi oleh factor atau variabel lainnya selain variable lingkungan kerja.

\section{d. Pembahasan}

Dalam hasil analisis deskriptif diatas dapat terlihat bahwa factor pencahayaan mendapatkan hasil sebesar 79,3\%, Sedarmayanti (2013) mengatakan bahwa cahaya yang kurang akan menyebabkan karyawan kurang efisien dalam melaksanakan pekerjaannya. Factor sirkulasi udara mendapatkan hasil 78,1\%, Sedarmayanti (2013) sirkuasi udara yang tidak baik akan mempercepat proses kelelahan sehingga pegawai tidak mencapai target kinerja mereka. Faktor kebisingan mendapatkan hasil 77,4\% , Sedarmayanti (2013) Kebisingan dapat mengganggu konsentrasi karyawan dalam bekerja. Faktor warna mendapatkan hasil 81\%, Sedarmayanti (2013) warna mempunyai pengaruh besar terhadap perasaan (mood) dalam bekerja. Kelembaban udara mendapatkan hasil 81,6\% , Sedarmayanti (2013) kelembaban udara akan mempengaruhi denyut jantung karena kelembaban udara yang tepat akan menyebabkan peredaran darah semakin aktif dalam memenuhi oksigen. Fasilitas mendapatkan hasil $78,4 \%$, Soetjipto dalam Gustian (2016) Fasilitas merupakan suatu penunjang untuk karyawan dalam menjalankan aktivitas dalam bekerja. Hubungan yang harmonis mendapatkan hasil 76,1\%, Soetjipto dalam Gustian (2016) hubungan yang harmonis dapat menguntungkan bagi perusahaan karena karyawan dapat mengembangkan diri tanpa ada batasan. Kesempatan untuk maju mendapatkan hasil $74,8 \%$, Soetjipto dalam Gustian (2016) kesempatan untuk maju merupakan suatu harapan bagi karyawan untuk menunjukkan prestasinya secara lebih baik dalam menjalankan pekerjaan.Keamanan dalam pekerjaan mendapatkan hasil 79,7\% Sedarmayanti (2013) perusahaan harus memastikan kondisi lingkungan kerja tetap dalam keadaan aman, agar tercipta keamanan dalam bekerja dan karyawan dapat bekerja secara maksimal.

Berdasarkan hasil analisis data, variabel $(\mathrm{X})$ lingkungan kerja memberikan pengaruh terhadap variable (Y) kinerja karyawan di suatu perusahaan di Jakarta. Hasil ini ditunjukkan oleh t-hitung 6,262 dengan signifikansi 0,000. Dengan t-hitung $(6,262)$ $>$ t-tabel $(2,045)$ dan signifikansi $0,000<0,05$, dimana dalam hal ini $\mathrm{H}_{0}$ ditolak serta $\mathrm{H}_{1}$ diterima. Dengan demikian, hipotesis yang diajukan yaitu "Lingkungan kerja berpengaruh signifikan terhadap kinerja karyawan pada suatu perusahaan di Jakarta" diterima. 
Kemudian besar pengaruh lingkungan kerja terhadap kinerja karyawan di suatu perusahaan di Jakarta dapat dilihat dari nilai $\left(\mathrm{R}^{2}\right)$ sebesar $57,5 \%$. Artinya besar pengaruh lingkungan kerja adalah $57,5 \%$, dan lainnya yaitu $42,5 \%$ dipengaruhi faktor atau variable lainnya.

\section{PENUTUP}

\subsection{Kesimpulan}

Kesimpulan dari pemaparan hasil diatas adalah ;

1. Lingkungan kerja karyawan pada suatu perusahaan di Jakarta masuk dalam kategori baik, dengan nilai rata-rata tanggapan responden $78,5 \%$.

2. Kinerja karyawanpada suatu perusahaan di Jakarta masuk dalam kategoribaik, dengan nilai rata-rata tanggapan responden $77,6 \%$.

3. Hasil dari pengujian hipotesis membuktikan bahwa lingkungan kerja berpengaruh positif dan signifikan terhadap kinerja karyawan pada suatu perusahaan di Jakarta.

Hal tersebut dibuktikan dengan koefisien regresi 0,386 yang benilai positif dan signifikansi $0,000<0,05$ serta t-hitung 6,262 $>$ t-tabel 2,045. Kemudian nilai $\left(R^{2}\right)$ yang didapatkan 0,575 . Artinyasebesar $57,5 \%$ dari kinerja karyawan di suatu perusahaan di Jakarta dipengaruhi oleh lingkungan kerja. Lainnya dengan score 42,5\% dipengaruhi oleh variabel lain yang tidak dibahas di penelitian ini.

\subsection{Saran}

1. Perusahaan perlu meningkatkan perhatian terhadap lingkungan kerja, khususnya indikator yang memiliki persentase terendah yaitu hubungan yang harmonis yang berarti perlu ditingkatkan sikap saling menghargai satu sama lain antar karyawan sehingga akan tercipta rasa kekeluargaan yang solid dan akhirnya berdampak kepada kinerja karyawan yang meningkat.

2. Meningkatkan kegiatan yang melibatkan kebersamaan didalam maupun diluar kantor dengan memanfaatkan fasilitas kantor semaksimal mungkin.

3. Katergori variabel lingkungan kerja termasuk dalam kategori baik, sehingga perusahaan hanya perlu mempertahankan ataumeningkatkan lingkungan kerja yang ada. Dalam melakukan perubahan lingkungan kerja fisik perusahaan juga harus memperhatikan lingkungan kerja non fisik agar kinerja karyawan lebih maksimal. Dengan merubah lingkungan kerja menjadi lebih baik diharapkan kinerja karyawan akan meningkat.

\section{E. DAFTAR PUSTAKA}

Budianto, A.A Tri (2015), Pengaruh Lingkungan Kerja Terhadap Kinerja Pegawai Pada PT. Perusahaan Gas Negara (Persero) Tbk SBU Distribusi Wilayah Jakarta,Jurnal Ilmiah Prodi Manajemen Universitas Pamulang, Vol. 3 No. 1

Bohang, Fatimah Kartini(2018),Nuansa Ceria dan Muda di Kantor Baru Google Indonesia. Kompas.com,04 Mei 1-2.

Darma, Budi (2019) Pengaruh Lingkungan Kerja Terhadap Kinerja Karyawan Pada Kantor Badan Perencanaan Pembangunan Daerah Kabupaten Batang Hari, Journal Economics and Business, Vol. 3 No. 1.

Gustian, Galant (2016), Pengaruh Disiplin dan Lingkungan Kerja Terhadap KinerjaKaryawan pada PD. Barokah Mandiri Bandung, Jurnal Ekonomi dan Manajemen, Vol. 11 No. 3

Hamali, Arif Yusuf (2016), Pemahaman Sumber Daya Manusia, Yogjakarta : CAPS. 
Ningrum, Nadia Lifa (2014) Pengaruh Lingkungan Kerja Terhadap Kinerja Karyawan (Studi pada Karyawan Auto 2000 Sukun Malang),Jurnal Administrasi Bisnis, Vol. 11 No. 1.

Rahmawanti (2014), Pengaruh Lingkungan Kerja Terhadap Kinerja Karyawan (Studi pada karyawan kantor pelayanan pajak pratama Malang Utara),Jurnal Administrasi Bisnis, Vol. 8 No. 2

Sedarmayanti (2013),Tata Kerja dan Produktivitas Kerja, Bandung : Mandar Maju.

Maju.

(2015),Sumber Daya Manusia dan Produktivitas Kerja, Bandung : CV Mandar

Siagian, Sondang P (2014), Manajemen Sumber Daya Manusia, Jakarta: PT. Bumi Aksara.

Sudarmanto (2015),Kinerja dan Pengembangan Kompetensi Sumber Daya Manusia, Cetakan ketiga, Yogjakarta : Pustaka Belajar.

Suwondo, Diah Indriani \& Sutanto, Eddy Madiono (2015),Hubungan Lingkungan Kerja, Disiplin Kerja dan Kinerja Karyawan pada Suatu Bank Cabang kota Malang, Jurnal Manajemen dan Kewirausahaan, Vol. 17 No. 2

Utomo,William Putra (2019), Indonesia Millenial Report 2019, IDN Media, diunduh tanggal 6 April 2020, dari https://cdn.idntimes.com/content-documents/indonesia-millennial-report2019-by-idntimes.pdf

Wirotama, Samahita (2017), Apa yang Dituntut Generasi Millenial di Tempat Kerja, diunduh tanggal 6 April 2020, dari https://samahitawirotama.com/apa-yang-dituntut-generasimilenial-di-tempat-kerja/ 